\title{
THE EFFECT OF NANO-BIOCHAR ON SOIL, WATER, AND NUTRIENT LOSS OF A SLOPING LAND WITH DIFFERENT VEGETATION COVERS ON LOESS PLATEAU OF CHINA
}

\author{
ZHOU, B. B. ${ }^{1 *}-$ CHEN, X. P. ${ }^{1}-$ HENRY, L. ${ }^{1,2}$ \\ ${ }^{1}$ State Key Laboratory of Eco-Hydraulic Engineering, Institute of Water Resources and Hydro- \\ electric Engineering, Xi'an University of Technology, Xi'an 710048, China \\ ${ }^{2}$ Department of Ecosystem Science and Management, Pennsylvania State University, State \\ College, PA 16802, USA \\ *Corresponding author \\ e-mail: happyangle222@aliyun.com
}

(Received $21^{\text {st }}$ Oct 2019; accepted $30^{\text {th }}$ Jan 2020)

\begin{abstract}
Nano-biochar with unique characteristics compared to common biochar has been confirmed to promote soil physical properties. Highly weathered soils in arid and semi-arid areas are characterized by low soil nutrients and high erosion potential. This study evaluated the influences of nano-biochar made from oak tree branches on the soil, water, and nutrient conservation on a sloping land of the Chinese Loess Plateau. Five nano-biochar rates $(0.0 \%, 0.1 \%, 0.5 \%, 0.7 \%$, and $1.0 \%$ by mass, equal to $0 \mathrm{t} / \mathrm{ha}$, $0.0263 \mathrm{t} / \mathrm{ha}, 0.131 \mathrm{t} / \mathrm{ha}, 0.184 \mathrm{t} / \mathrm{ha}, 0.268 \mathrm{t} / \mathrm{ha}$ ) were applied in three bands with simulated rainfall plots (1.0 $\mathrm{m}$ in length, $1.0 \mathrm{~m}$ in width) with five different vegetation covers (bare, alfalfa, bean, Caragana microphylla, and corn). A simulated typical rainfall event of $90 \mathrm{~mm} \mathrm{~h}^{-1}$ was performed for all the treatments. Experimental results indicated that the initial runoff time was delayed with the increasing nano-biochar contents. Compared to the treatments with no biochar application, soil, water, and nutrient losses in runoff significantly decreased. The conservation effect of nano-biochar was the most significant in the alfalfa plot. Soil containing $0.7 \%$ nano-biochar $(0.131 \mathrm{t} / \mathrm{ha})$ with alfalfa planting mollusc. This study provides an effective method for soil water and nutrient conservation.
\end{abstract}

Keywords: nano-biochar, soil and water loss control, nutrient loss and conservation, conservation value, vegetation cover

\section{Introduction}

Semi-arid loess region of northwestern China has been suffering from severe soil erosion (up to 1000-15,000 t/ $\mathrm{km}^{2}$ per year) and nutrient loss (Shi et al., 2000; Chen et al., 2008), which is the primary cause of soil degradation and water pollution (Guo et al., 2013). In order to control the serious soil water erosion and nutrient loss, huge researches have been conducted since the end of 1950s (Huang et al., 2015). Over the years, China government has taken various conservation measures to solve this serious soil and water erosion, as well as nutrient loss problems, such as minimum tillage and no-tillage, Hedgerows, and straw mulch (Lin et al., 2009; Wang et al., 2017; Rahma et al., 2017). However, in practical terms, the effects were quite limited because of different perceived problems. Minimum tillage and no-tillage resulted in more weeds and lower yield than conventional tillage (Wozniak and Kwiatkowski, 2013; Beibei Zhou, et al., 2016). Hedgerows would also consume water, nutrient and sunlight which will reduce crop yields, besides the existence of hedgerows will also make tillage inconvenient (Sun et al., 2001). Straw mulch could be an adoptable method which could help with reducing soil and water runoff, as well as evaporation, but the straw will be washed away when the storm came (Peng et al., 2016; Li et al., 2017). Thus, to find an 
appropriate and effective method in controlling soil, water erosion and nutrient loss on the Loess Plateau remains an urgent task.

Moreover, soils in semi-arid loess region of northwestern China have high silt content, low organic matter content, and poor soil structure, which is difficult to overcome. The poor soil condition, combined with inappropriate land use, makes soil and nutrient loss very vulnerable to rainfall. Since the 1990s, kinds of soil amendments have been widely studied in order to control soil erosion and nutrient loss, such as polyacrylamides (PAM) and biochar (or black carbon) (Busscher et al., 2011; Wang et al., 2013). The PAM has been proved to control soil and water erosion for a long time, but PAM could also restrict infiltration which in turn accelerates runoff ( $\mathrm{Lu}$ and Wang, 2016). The increased runoff will facilitate erosion in the downslope with villages that may turn out to be a big disaster. Besides, PAM belongs to water-soluble polyacrylamide and its limited capability in improving soil structures and quantity makes the PAM less feasible for soil and water conservation. Because of the high porosity and large inner surface area, biochar has been widely used to improve soil physical properties, especially soil water holding capacity since the 2000s (Hina et al., 2010; Herath et al., 2013; Li, 2017). Moreover, lots of studies have shown that biochar is promising to ameliorate soil physicochemical properties, improve nutrient utilization and crop yield (Laird et al., 2010; Mukherjee and Zimmerman, 2013). However, high biochar rate such as 40 to 50 tons per hectare is usually suggested (Cheng et al., 2015; Nguyen et al., 2010; Li et al., 2017). The high biochar rate together with its high mobility with storm runoff largely limits the biochar application.

Compared with common biochar, nano-biochar made of tree branches is also a carbon-rich product, which has similar properties as common biochar. Furthermore, due to the small size, nano-biochar could also achieve similar properties to nano material which have strong absorption. But little research has been done. The objective of this study was to examine the impact of nano-biochar applied into a sloping land on soil erosion, water runoff, as well as nutrient loss under five vegetation species on Loess Plateau of China using simulated rainfalls.

\section{Materials and methods}

\section{Experimental site}

The experiment was done at Liudaogou watershed $\left(35^{\circ} 20^{\prime}-40^{\circ} 100^{\prime} \mathrm{N}, 110^{\circ} 21^{\prime}-\right.$ $110^{\circ} 23^{\prime} \mathrm{E}$ ), which is located in the northern part of the Chinese Loess Plateau. The catchment is $6.89 \mathrm{~km}^{2}$ and the elevations is between 1,081 and $1,274 \mathrm{~m}$ which belong to semi-arid area. The annual average temperature of the experiment site is $8.4^{\circ} \mathrm{C}$ with the lowest temperature $-9.7^{\circ} \mathrm{C}$ in January and the highest temperature $23.7^{\circ} \mathrm{C}$ in July. The annual mean rainfall is about $437 \mathrm{~mm}$ with the minimum rainfall of $109 \mathrm{~mm}$ and maximum rainfall of $891 \mathrm{~mm}$. The underground water level is more than $20 \mathrm{~m}$.

\section{Experimental plots}

In this study, five nano-biochar application rates $(0.0 \%, 0.1 \%, 0.5 \%, 0.7 \%$, and $1.0 \%$, equal to $0 \mathrm{t} / \mathrm{Ha}, 0.0263 \mathrm{t} / \mathrm{ha}, 0.131 \mathrm{t} / \mathrm{ha}, 0.184 \mathrm{t} / \mathrm{ha}, 0.268 \mathrm{t} / \mathrm{ha}$ ) and five vegetation types (i.e., bare, alfalfa, bean, Caragana microphylla and corn) were considered, so the total number of the treatments were 25 , together with one plot in bared soil without 
nano-biochar which was used as the control. Each treatment was conducted in one plot with $1 \mathrm{~m}$ in length and $1 \mathrm{~m}$ in width.

To study how the nano-biochar affect the soil and nutrient loss, the nano-biochar was mixed well with soils and then applied in bands $(5 \mathrm{~cm}$ wide, $200 \mathrm{~cm}$ long, and $5 \mathrm{~cm}$ thick) 5-10 cm under the surface. The bands were located at top, middle, and bottom of the plot shown in Figure 1, respectively. Before nano-biochar was applied into the plots, soils of top $10 \mathrm{~cm}$ in the band were removed. The nano-biochar was then mixed uniformly with half of the removed soils at a mass rate of $0.0 \%$ (control), 0.1, 0.5, 0.7, and $1.0 \%$ of nano-biochar, respectively, to make a $5 \mathrm{~cm}$-thick soil nano-biochar mixture layer in the original position. Finally, the other half of the removed top soil was piled onto the soil nano-biochar mixture layer with its original bulk density. To minimize the possible influences by human disturbance, the mixtures-buried plots were sitting for four months before rainfall simulation experiments.

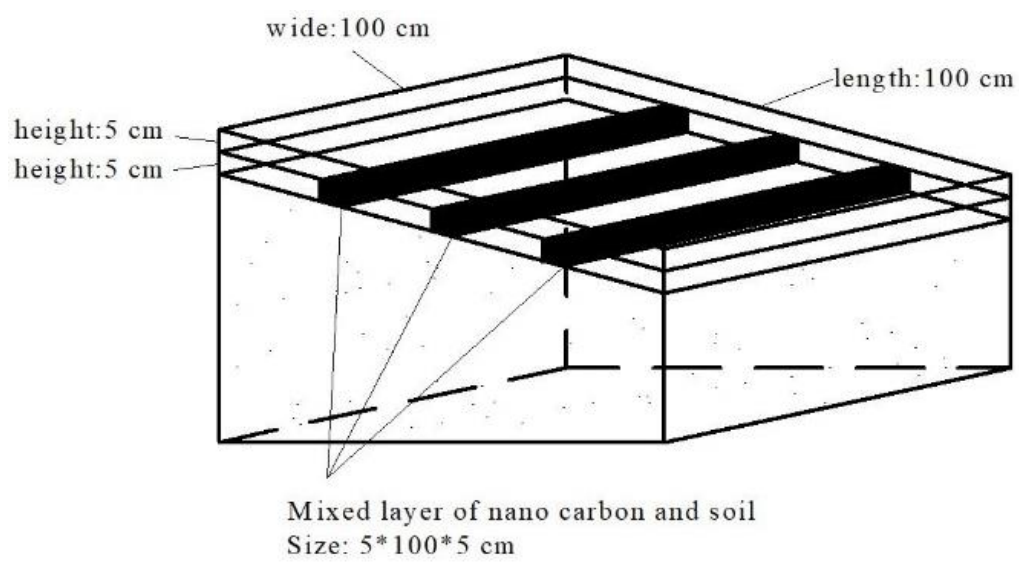

Figure 1. The position of nano-biochar bands applied in the plot $(1 \mathrm{~m} \times 1 \mathrm{~m})$

The plants were seeded 3 months before experiments. Before the rainfall experiment was conducted, vegetation was trimmed to similar vegetation coverage (Table 1). To reduce the disturbance due to agriculture, the vegetation specified above was planted in the plots and left undisturbed for a period of $4 \mathrm{~m}$ before simulated rainfall after NB was applied to the soil. Caragana microphylla and alfalfa were drill sown, with rows spaced $25 \mathrm{~cm}$ apart; corn and bean were bunch planted, with rows spaced $25 \mathrm{~cm}$ apart and individual plants were spaced $35 \mathrm{~cm}$ apart in each row. Planting and field management of vegetation were carried out according to local farming practices. Status of vegetation growth was taken before the simulated rainfall. Vegetative coverage of Caragana microphylla and corn was $45.93 \%$ and $42.39 \%$ on slope of plot area, respectively, which could represent the local general situation. The vegetation coverage was calculated with Matlab software. Each plot has an average slope of $152^{\circ}$.

Table 1. Vegetation growth status in the experimental area

\begin{tabular}{c|c|c|c}
\hline Vegetation species & Height $\mathbf{( c m )}$ & Leaf area of a single plant $\left.\mathbf{( c m}^{\mathbf{2}}\right)$ & Vegetation coverage \\
\hline Corn & $84.3-93.9$ & $163.2-201.5$ & $41.4 \%$ \\
Bean & $36.7-45.8$ & $25.1-34.7$ & $42.3 \%$ \\
Alfalfa & $41.3-49.6$ & $1.2-2.7$ & $43.3 \%$ \\
Caragana microphylla & $54.1-71.3$ & $0.9-1.5$ & $43.9 \%$ \\
\hline
\end{tabular}


The physical and chemical characteristics of the experimental soil are shown in Table 2. The experimental soil was sandy textured which belonged to the Aeolian sandy soil (Hillel, 1982).

Table 2. Physical and chemical properties of the experimental soil

\begin{tabular}{c|c|c|c|c|c}
\hline Clay (\%) & Silt $(\%)$ & Sand (\%) & Soil texture & Organic content $\left(\mathbf{g ~ k g}^{-1}\right)$ & $\mathbf{p H}$ \\
\hline 5.5 & 30.5 & 64.0 & Sandy & 3.5 & 6.2 \\
\hline
\end{tabular}

\section{Physical and chemical properties of nano-biochar}

The nano-biochar applied in this experiment was provided by the Hainuo Nano Company (Shanghai, China) and produced by oak tree branches over 5-6 h at $500{ }^{\circ} \mathrm{C}$. The diameter of nano-biochar was less than $40 \mathrm{~nm}$. Its physics-chemical properties are shown in Table 3.

Table 3. Basic properties of the nano-biochar used in this study

\begin{tabular}{|c|c|c|c|c|c|}
\hline pH & $\begin{array}{l}\text { Water content } \\
\quad\left(\mathrm{kg} \mathrm{kg}^{-1}\right)\end{array}$ & $\begin{array}{l}\text { Ash content } \\
\quad\left(\mathrm{kg} \mathrm{kg}^{-1}\right)\end{array}$ & $\begin{array}{l}\text { Bulk density } \\
\qquad\left(\mathrm{g} \mathrm{cm}^{-3}\right)\end{array}$ & $\begin{array}{c}\text { Iodine sorption } \\
\text { value }\left(\mathrm{mg} \mathrm{g}^{-1}\right)\end{array}$ & $\begin{array}{c}\text { BET } \\
\left(\mathrm{m}^{2} \mathrm{~g}^{-1}\right)\end{array}$ \\
\hline 9.6 & $5 \%$ & $60.0 \%$ & 0.38 & 1,300 & 1,300 \\
\hline
\end{tabular}

*BET refers to Brunauer, Emmett and Teller, which is a classical method to measure the specific area of particles

\section{Rainfall simulation}

The simulated rainfall experiments were conducted in the plots shown in Figure 1 using a pinhole rainfall device invented by Zhou and Hu (2015) (Fig. 2) from June to September of 2016. The raindrops of $2.5 \mathrm{~mm}$ could be produced from the tubes of the simulated rainfall device $2.0 \mathrm{~m}$ above the plant canopy in experimental plots. The simulated rainfall intensity of this study was $90 \mathrm{~mm} \mathrm{~h}^{-1}$ (Chen and Zhou, et al., 2019), which is the average rainfall intensity in summer of the local. The simulated rainfall experiment will last for 40 min after the runoff occurred.

Before the simulated rainfall experiment, a mixed solution with $1.0 \mathrm{~mol} \mathrm{~L}^{-1}$ potassium bromide $(\mathrm{KBr}), 1.0 \mathrm{~mol} \mathrm{~L}-1$ potassium nitrate $\left(\mathrm{KNO}_{3}\right)$, and $1.0 \mathrm{~mol} \mathrm{~L}^{-1}$ monopotassium phosphate $\left(\mathrm{KH}_{2} \mathrm{PQ}_{4}\right)$ was sprayed on the soil surface. The application rate for each individual solution was $40 \mathrm{~g} \cdot \mathrm{m}^{-2}$. The water runoff and soil sediment will be collected at the low end of each plot. Once the water runoff started, the runoff samples (volume depending on time and the plot) will be collected with a plastic bottle every $3 \mathrm{~min}$. All the samples were then transported in an ice box to the laboratory where samples will be analyzed immediately. The concentrations of $\mathrm{NO}_{3}{ }^{-} \mathrm{N}, \mathrm{K}^{+}, \mathrm{PO}_{4}^{-3}$, together with the total solids ( $T_{\mathrm{s}}$, representing sediment) in runoff and soil sediment samples were measured by the ultraviolet spectrophotometric method, atomic absorption spectrophotometer HG-9602A, and standard methods, respectively (Bao, 2005).

After the first simulated rainfall experiment was finished, the plot was left for a period of time (depending the weather, mostly, it will usually be one month) until the soil water content measured by oven dry method dropped back to the status right before 
the first rainfall simulation. Then another replication of rainfall simulation was conducted in the same way.

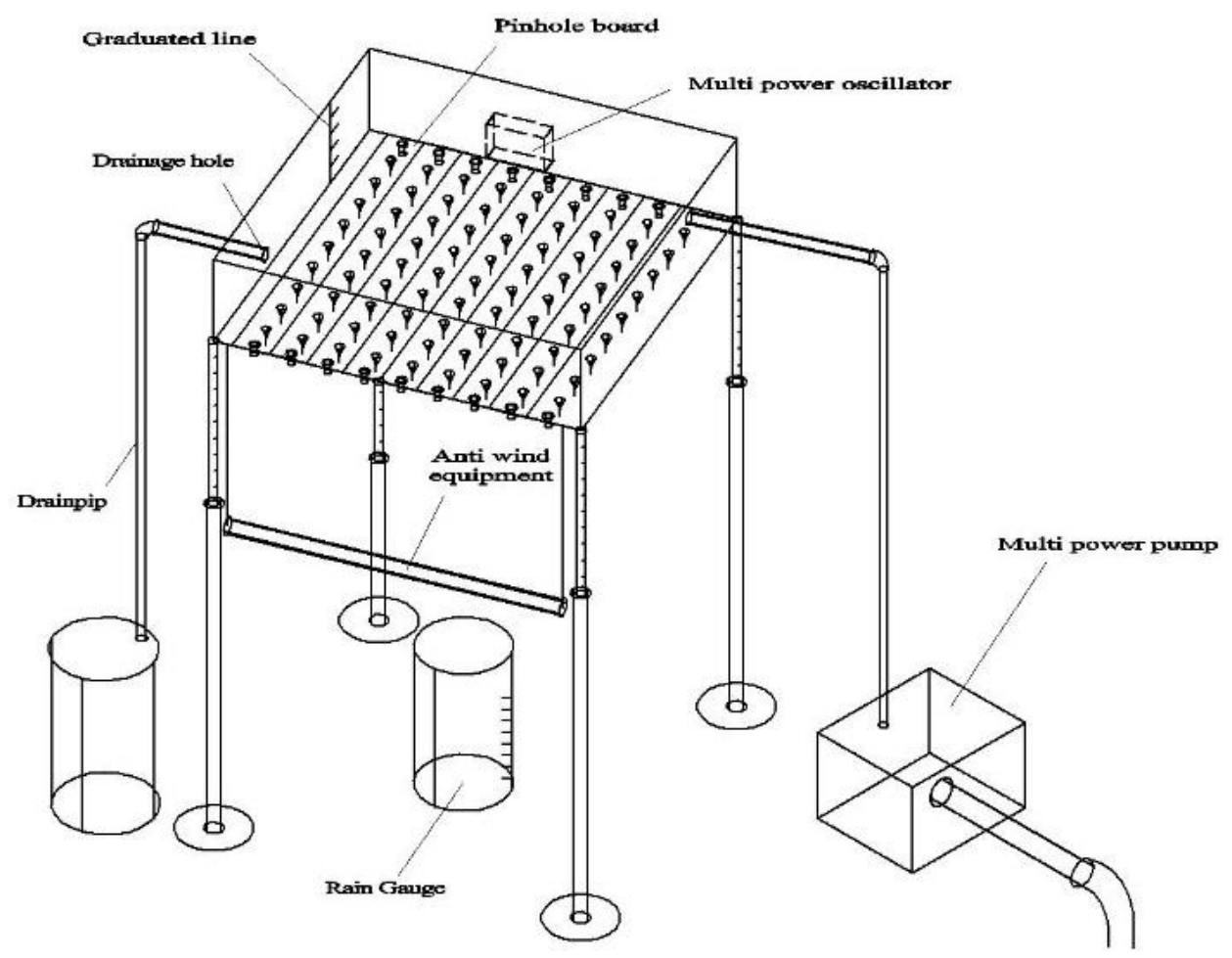

Figure 2. Pinhole type simulated rainfall device for experiments on effect of rainfall on erosion on the Loess Plateau, China

Conservation value $\left(C_{\mathrm{v}}\right)$ of soil, water, and nutrients for each treatment was calculated with the equation as follows (Kumar et al., 1992):

$$
c_{v}=\left(1-\frac{s_{p}}{s_{\mathrm{n}}}\right) \times 100 \%
$$

where $S_{\mathrm{p}}, S_{0}$ are the total amount of soil, water, or nutrient loss from the experimental plots and control plots, respectively.

\section{Statistical analysis}

Analysis of variance (ANOVA) method was used to determine the effect of nanobiochar contents and vegetation species on water runoff, soil erosion, as well as nutrient loss.

\section{Results and discussion}

\section{Nano-biochar contents affect water runoff and soil erosion}

\section{Effect of nano-biochar contents on initial runoff time}

In order to know the effect of nano-biochar on initial runoff time is one of the important parameters for characterizing runoff. The initial runoff time increased with 
an increase in nano-biochar contents (Table 4), indicating that the nano-biochar delayed the runoff generation. Infiltration excess overland flow is the main reason of runoff on the slope in the semi-arid loess region of China. Based on the laboratory experiment of $\mathrm{Lv}$ et al. (2016), the result indicated the nano-biochar applied $5 \mathrm{~cm}$ under the soil surface can increase the infiltration rate obviously. So in this study, the increased infiltration rate delayed the initial runoff time comparing to that in control plot. Moreover, the effect of nano-biochar on the initial runoff time was more pronounced when the nano-biochar content was larger than $0.5 \%$. However, when nano-biochar content approached to $1.0 \%$, the effect became weak (Table 4). Similar results were obtained by Sadeghi et al. (2016), of which it showed an effective impact of biochar application on delaying runoff time by 55\% comparing to that in control experiment.

Table 4. Effect of nano-biochar content on initial runoff time in minute

\begin{tabular}{c|c|c|c|c|c}
\hline \multirow{2}{*}{ Vegetation type } & \multicolumn{5}{c}{ Nano-biochar content $(\boldsymbol{\%})$} \\
\cline { 2 - 6 } & $\mathbf{0}$ (control) & $\mathbf{0 . 1}$ & $\mathbf{0 . 5}$ & $\mathbf{0 . 7}$ & $\mathbf{1 . 0}$ \\
\hline Bare (control) & 5.2 & 5.5 & 8.0 & 7.5 & 8.4 \\
Alfalfa & 15.2 & 20.0 & 29.5 & 29.6 & $/$ \\
Bean & 11.8 & 12.2 & 13.2 & 14.3 & 14.3 \\
Caragana microphylla & 13.1 & 13.3 & 13.9 & 14.1 & 14.5 \\
Corn & 12.0 & 12.8 & 13.2 & 13.4 & 13.4 \\
\hline
\end{tabular}

"/" represents no runoff. The values in this table were average values

The initial runoff time in the plots with vegetation cover lagged behind as compared with the control plot (Table 4), indicating that vegetation also delayed the runoff time. The main reason is that the presence of the vegetation root could effectively prevents runoff, together with plant interception impact. As a result, vegetal cover provided sufficient time for infiltration and slowed down the runoff commence (Marques et al., 2007). Alfalfa followed by Caragana microphylla was the most efficient species to delay runoff, which was in agreement with a previous study (Wu et al., 2011). The dense vegetal cover and well-developed root of alfalfa and Caragana microphylla may contribute to the slower movement of simulated rainfall. Therefore, planting alfalfa and Caragana microphylla with band application of nanobiochar $(\geq 0.5 \%$ or $0.488 \mathrm{t} / \mathrm{ha}$ ) would be a good method to slow down the runoff on the sloping land in the study area.

\section{Effect of nano-biochar content on water runoff and soil loss}

Table 5 shows the amount of runoff and soil loss and associated $C_{\mathrm{v}}$ values of various vegetation species and nano-biochar contents averaged for two simulated rainfall events. The maximum amount of runoff and soil loss was obtained in the bare plot with no nano-biochar. With the increase of nano-biochar content, the runoff was reduced from 3,911 to $2,538 \mathrm{~cm}^{3}$ and the soil loss (sediments) was reduced from $565 \mathrm{~g}$ to $239 \mathrm{~g}$. No water runoff and soil loss were obtained in alfalfa plot with $1 \%$ of nano-biochar. The runoff amount was significantly reduced when nano-biochar amendments were used, and almost kept unchanged when the nano-biochar content was $0.7-1.0 \%$ (Table 5 ). The decreasing amount of soil loss also clearly confirmed the benefit of nano- 
biochar in improving field water holding capacity and conserving soil particles. Water runoff and soil erosion in vegetal plots with nano-biochar were generally reduced compared with the control plot which showed the maximum runoff. This was because vegetal cover slowed down water movement and rendered more time for infiltration thereby less runoff. Among plots with no nano-biochar, the alfalfa plot showed the minimum runoff $(1,008 \mathrm{~mL})$ and soil loss $(58 \mathrm{~g})$, with $C_{\mathrm{v}}$ values of $74.2 \%$ and $81.9 \%$, respectively. This again indicated that alfalfa was the most efficient species in soil and water conservation especially when nano-biochar content was $1 \%$, runoff was eliminated. Caragana microphylla was the second most efficient species showing $C_{\mathrm{v}}$ values of $48.7 \%$ and $54.1 \%$, respectively, for runoff and soil loss.

Table 5. Effect of nano-biochar content on runoff, soil loss, and associated conservation values $\left(C_{v}\right) *$

\begin{tabular}{|c|c|c|c|c|c|}
\hline Vegetation species & $\begin{array}{c}\text { Nano-biochar } \\
\text { content }(\%)\end{array}$ & $\begin{array}{c}\text { Runoff } \\
\text { amount }(\mathrm{mL})\end{array}$ & $C_{\mathrm{v}}$ for water $(\%)$ & Soil loss (g) & $C_{\mathrm{v}}$ for soil $(\%)$ \\
\hline \multirow{5}{*}{ Bare (control) } & 0 (control) & 3911.1 & $\mathrm{~N} A$ & 565.0 & $\mathrm{~N} A$ \\
\hline & 0.1 & 3889.0 & 23.6 & 397.3 & 29.7 \\
\hline & 0.5 & 3484.5 & 36.5 & 336.1 & 40.5 \\
\hline & 0.7 & 3158.6 & 19.2 & 257.3 & 54.5 \\
\hline & 1.0 & 2537.5 & 35.1 & 239.2 & 57.7 \\
\hline \multirow{5}{*}{ Alfalfa } & 0 & 1007.9 & 74.2 & 57.8 & 89.8 \\
\hline & 0.1 & 875.6 & 77.6 & 77.1 & 86.4 \\
\hline & 0.5 & 768.5 & 80.4 & 65.1 & 88.5 \\
\hline & 0.7 & 617.6 & 84.2 & 22.2 & 96.1 \\
\hline & 1.0 & 1 & 100.0 & I & $\mathrm{N} A$ \\
\hline \multirow{5}{*}{ Bean } & 0 & 2334.5 & 48.0 & 356.4 & 36.9 \\
\hline & 0.1 & 2199.9 & 43.8 & 342.4 & 39.5 \\
\hline & 0.5 & 2120.3 & 45.8 & 324.6 & 42.6 \\
\hline & 0.7 & 1768.4 & 54.8 & 317.6 & 43.8 \\
\hline & 1.0 & 1703.4 & 56.5 & 243.3 & 56.9 \\
\hline \multirow{5}{*}{$\begin{array}{l}\text { Caragana } \\
\text { microphylla }\end{array}$} & 0 & 2005.0 & 48.7 & 259.3 & 54.1 \\
\hline & 0.1 & 1677.8 & 57.1 & 220.3 & 61.0 \\
\hline & 0.5 & 1251.8 & 68.0 & 169.9 & 69.9 \\
\hline & 0.7 & 1204.4 & 69.2 & 194.8 & 65.5 \\
\hline & 1.0 & 1439.9 & 63.2 & 151.0 & 73.3 \\
\hline \multirow{5}{*}{ Corn } & 0 & 2555.3 & 34.7 & 348.6 & 38.3 \\
\hline & 0.1 & 2637.9 & 32.6 & 289.9 & 48.7 \\
\hline & 0.5 & 2119.3 & 45.8 & 259.9 & 54.0 \\
\hline & 0.7 & 2311.8 & 40.9 & 246.8 & 56.3 \\
\hline & 1.0 & 1913.1 & 51.1 & 204.8 & 63.8 \\
\hline
\end{tabular}

" " refers to no runoff. *All the data shown in Table 5 are averaged values of two simulated rainfall events

The observed behavior has a much more good results comparing to the previous studies reported by Smetanová et al. (2013) who indicated that $10 \%$ biochar in mass 
could reduce runoff events by more than $40 \%$. In this study, nano-biochar could reduce $0.57-43.5 \%$ runoff in bare land, $74.2 \%-100 \%$ runoff in alfalfa land, 40.3-87.0\% runoff in bean land, 48.7-97.4\% runoff in Caragana microphylla land, and 34.7-78.7\% runoff in corn land. The significant effect of nano-biochar on reducing runoff production could be attributed to the strong water capacity of nano-biochar and increasing infiltration rate (Lv et al., 2016; Li et al., 2017).

Water drops triggered soil erosion and soil deposition at the outlet of bared plots (Srivastava and Singh, 2012). Artificial rain drops also broke soil clumps into finer particles, which made the soil easily be carried over by runoff. For all the plots with nano-biochar, however, the runoff was reduced due to the increased infiltration and absorption. The effect of reducing runoff was larger at a higher rate of nano-biochar application. For the vegetated plots, the vegetation intercepted water drops and formed local hindrance to free and fast movement of water. Besides, runoff always moved down the slope more strongly forming narrowing channels in the bared plots, whereas the vegetated plots reduced the free flow of runoff and therefore reduced soil loss. The vegetation roots and nano-biochar also bound soil firmly and prohibited soil moving along the slope. Corn did not have abundant roots. This may explain why corn was the least efficient species in reducing soil loss.

The ANOVA analysis indicated that both nano-biochar content and vegetation cover had significant ( $p<0.001$ ) effects on soil and water conservation (Tables 6 and 7). Based on the discussion above, planting alfalfa with application of nano-biochar at a rate of $0.5 \%$ would be an efficient and economic method to reduce water and soil loss on Loess Plateau of China.

Table 6. Analysis of variance (ANOVA) for the effect of nano-biochar content and vegetation species on runoff and soil loss

\begin{tabular}{c|c|c|c|c|c}
\hline Source & Sum of squares & Degree of freedom & Mean sum of square & $\boldsymbol{F}$-statistic & $\boldsymbol{p}$-value \\
\hline \multicolumn{6}{c}{ Runoff } \\
\hline Nano-biochar & $3.8 \mathrm{E}+07$ & 4 & $9.5 \mathrm{E}+06$ & 14.4 & $<0.001$ \\
Vegetation & $3.0 \mathrm{E}+08$ & 4 & $7.5 \mathrm{E}+06$ & 114.5 & $<0.001$ \\
Error & $1.1 \mathrm{E}+07$ & 16 & $6.6 \mathrm{E}+06$ & & \\
Total & $3.5 \mathrm{E}+08$ & 49 & Soil loss \\
\hline \multicolumn{6}{c}{} \\
\hline Nano-biochar & $2.5 \mathrm{E}+04$ & 4 & $6.3 \mathrm{E}+03$ & 8.7 & $<0.001$ \\
Vegetation & $1.7 \mathrm{E}+05$ & 4 & $4.2 \mathrm{E}+04$ & 58.2 & $<0.001$ \\
Error & $1.2 \mathrm{E}+04$ & 16 & $7.2 \mathrm{E}+02$ & & \\
Total & $2.1 \mathrm{E}+05$ & 24 & & \\
\hline
\end{tabular}

\section{Effect of nano-biochar content on nutrient loss}

\section{Effect of nano-biochar on nutrient loss in runoff}

Loss of nutrients (i.e., $\mathrm{NO}_{3}{ }^{-} \mathrm{N}, \mathrm{K}^{+}, \mathrm{PO}_{4}^{-3}$ ) in the runoff presented the same temporal trend for different treatments except for the control plot in the first $10 \mathrm{~min}$ (Figs. 3-5). Concentration of all three ions increased over time approximately in the first $10 \mathrm{~min}$ followed by a constant or slowly decreased nutrient concentration. The solute 
concentration in the runoff at the early stage was mainly caused by the raindrops and solute concentration in subsurface of the plot. Few minutes after the water runoff production, more solute will be found in the runoff which was transferred from the surface. In the control plot, however, the nutrient on the surface was washed downward directly as there were no nano-biochar or vegetation to prevent runoff. As such, concentration of nutrients in the runoff reached a relatively high values in a short time, and dropped quickly due to the fast attenuation of nutrients in the surface layer. The solute concentration in the runoff was controlled by diffusion from the soil at the later stage. This resulted in a stabilized concentration of solute in the runoff. The higher solute concentration in the soil usually led to more solute loss with runoff. But the runoff was reduced remarkably with application of nano-biochar, especially at rates greater than $0.5 \%$. The nano-biochar was, therefore, confirmed to reduce the nutrient loss due of the reduction of runoff and strong absorption capacity.

Table 7. Effect of nano-biochar on nutrient loss and conservation value $\left(C_{v}\right)$ in runoff

\begin{tabular}{|c|c|c|c|c|c|c|c|}
\hline $\begin{array}{c}\text { Vegetation } \\
\text { species }\end{array}$ & $\begin{array}{c}\text { NB content } \\
(\%)\end{array}$ & $\begin{array}{c}\mathrm{NO}_{3}-\mathrm{N} \text { loss } \\
(\mathrm{mg})\end{array}$ & $\begin{array}{c}C_{\mathrm{v}} \text { for } \\
\mathrm{NO}_{3}-\mathrm{N}(\%) \\
\end{array}$ & $\begin{array}{c}\text { P loss } \\
(\mathrm{mg})\end{array}$ & $\begin{array}{c}C_{\mathrm{v}} \text { for } \mathrm{P} \\
(\%)\end{array}$ & $\begin{array}{c}\text { K loss } \\
(\mathrm{g})\end{array}$ & $\begin{array}{c}C_{\mathrm{v}} \text { for } \mathrm{K} \\
(\%)\end{array}$ \\
\hline \multirow{5}{*}{ Bare } & 0 & 4.5 & 1 & 2.46 & 1 & 16.7 & I \\
\hline & 0.1 & 2.5 & 44.1 & 1.62 & 33.8 & 10.8 & 35.4 \\
\hline & 0.5 & 1.5 & 65.5 & 1.10 & 75.5 & 7.5 & 55.4 \\
\hline & 0.7 & 1.6 & 63.3 & 1.44 & 68.0 & 9.9 & 40.8 \\
\hline & 1 & 1.7 & 63.2 & 0.87 & 80.5 & 6.4 & 61.5 \\
\hline \multirow{5}{*}{$\begin{array}{c}\text { Caragana } \\
\text { microphylla }\end{array}$} & 0 & 1.8 & 59.3 & 0.93 & 79.2 & 4.23 & 74.7 \\
\hline & 0.1 & 1.0 & 77.7 & 0.57 & 87.3 & 3.897 & 76.7 \\
\hline & 0.5 & 0.8 & 83.2 & 0.53 & 88.2 & 3.76 & 77.5 \\
\hline & 0.7 & 0.5 & 88.4 & 0.57 & 87.3 & 6.566 & 60.7 \\
\hline & 1 & 0.7 & 85.4 & 1.13 & 74.9 & 6.539 & 60.9 \\
\hline \multirow{5}{*}{ Alfalfa } & 0 & 0.9 & 81.1 & 0.54 & 88.0 & 3.2 & 80.7 \\
\hline & 0.1 & 0.6 & 87.7 & 0.31 & 93.2 & 2.5 & 85.3 \\
\hline & 0.5 & 0.4 & 91.2 & 0.28 & 93.7 & 2.0 & 88.3 \\
\hline & 0.7 & 0.3 & 92.7 & 0.20 & 95.5 & 1.6 & 90.5 \\
\hline & 1 & 1 & 100.0 & 1 & 100.0 & 1 & 100.0 \\
\hline \multirow{5}{*}{ Bean } & 0 & 2.6 & 42.8 & 1.31 & 70.8 & 9.5 & 43.3 \\
\hline & 0.1 & 1.8 & 58.9 & 0.99 & 78.0 & 7.5 & 55.1 \\
\hline & 0.5 & 1.4 & 69.7 & 0.80 & 82.2 & 6.2 & 62.7 \\
\hline & 0.7 & 1.0 & 78.7 & 0.52 & 88.4 & 4.9 & 70.5 \\
\hline & 1 & 0.9 & 79.0 & 0.63 & 85.9 & 4.5 & 73.1 \\
\hline \multirow{5}{*}{ Corn } & 0 & 2.9 & 35.5 & 1.75 & 61.0 & 10.672 & 36.2 \\
\hline & 0.1 & 2.0 & 54.8 & 1.28 & 71.5 & 8.478 & 49.3 \\
\hline & 0.5 & 1.4 & 68.7 & 0.91 & 79.6 & 5.702 & 65.9 \\
\hline & 0.7 & 1.4 & 69.6 & 0.79 & 82.4 & 5.781 & 65.4 \\
\hline & 1 & 0.8 & 82.3 & 0.64 & 85.7 & 4.197 & 74.9 \\
\hline
\end{tabular}

NB is short for nano-biochar 
The loss quantity of three ions varied greatly because of different chemical properties. As nitrate nitrogen is always lost through runoff and leaching, the amount of runoff would directly affect the quantity of nitrate nitrogen loss in runoff. From Figures 3-5, it could be found that in the initial $10 \mathrm{~min}$, the nitrate nitrogen loss in runoff increased continuously in the soil surface after the simulated rainfall started. Subsequently, the nitrate nitrogen loss reduced gradually. As a result, the total nitrates loss at the initial time was about 4 times of that at the end of the experiment. The main reason is that at the beginning of runoff, the soil has a much higher clay particle which could absorb more nitrate nitrogen and more nitrate nitrogen was kept in soil water. So high nitrate contents could be obtained at the initial stage in runoff. With the reduce of nitrate nitrogen and the increase of mixed layer depth, nitrate was reduced gradually. Besides, the nitrate nitrogen loss was reduced obviously in the plots with nano-biochar, especially when the nano-biochar contents were $0.7 \%$ and $1.0 \%$. The cumulative loss of nitrate nitrogen in the control treatment was much higher than that of others, which further indicating that the application of nano-biochar in soil could effectively reduce the loss of nitrate in the soil. Furthermore, the cumulative loss of nitrate in runoff was negatively correlated with increased nano-biochar contents. In bare, the runoff of each treatment with different nanobiochar reduced nitrite loss by $29.9-42.7 \%$. With more nano-biochar was applied, more nitrate was kept in soil profile which could attribute to the excellent properties of nanobiochar, such as an enormous specific surface area, rich pore structure, and strong adsorption capacity (Deborah et al., 2011). As a result, can reduce the loss of nutrients by absorbing nutrient ions, preventing deep leaching from the surface soil.

Similar to nitrate nitrogen, at the initial time of the rainfall, more phosphorus was kept in soil water or be absorbed in soil particle, so the loss of phosphorus in runoff also first increased sharply in the initial 10 min (Vadas and Busch et al., 2015). The soil on Loess Plateau, has a poor structure, which prevent phosphorus from deep leaching but make phosphorus easily involved in runoff (Yan et al., 1999). As a result, the phosphorus loss tended to be stable. While with the increase of nano-biochar, the loss of phosphorus in runoff was also reduced.

Potassium was easily dissolved in soil water and runoff, so the potassium loss in runoff was much greater than that of other two nutrients for all the treatments (Poss et al., 2010). But the potassium loss also increased in the early $10 \mathrm{~min}$ and then became constant. Moreover, the effect became more significant at a higher rate of nano-biochar content.

In order to further analyze how nano-biochar affect nutrient loss, the nutrient loss and nutrient conservation values in runoff were calculated (Table 8). Nano-biochar effectively reduced the nutrient loss. With the increase of nano-biochar content, the nutrient loss was reduced and nutrient conservation value increased, especially when the nano-biochar content was $0.7 \%$ and $1.0 \%$. Furthermore, nutrient conservation values of phosphorus, which is the main element to contribute to eutrophication, were much greater than those of nitrate nitrogen and potassium. The main reason was that the chemical interactions between phosphorus and clay minerals (Dutta, 2007; Tomer et al., 2007) largely reduced the mobility of phosphorus in soils except very sandy or organic soils. Most of the phosphorus was lost with the eroded soil particles. Vegetation species also affected the amount of nutrient loss in runoff (Figs. 3-5; Table 8). The bared plots showed the highest amount of nutrient loss in the surface runoff. Plots with alfalfa followed by Caragana microphylla showed the lowest amount of nutrient loss and highest nutrient conservation values. This indicated that nano-biochar application with planting alfalfa and Caragana microphylla had a positive influence in conserving nutrient. 

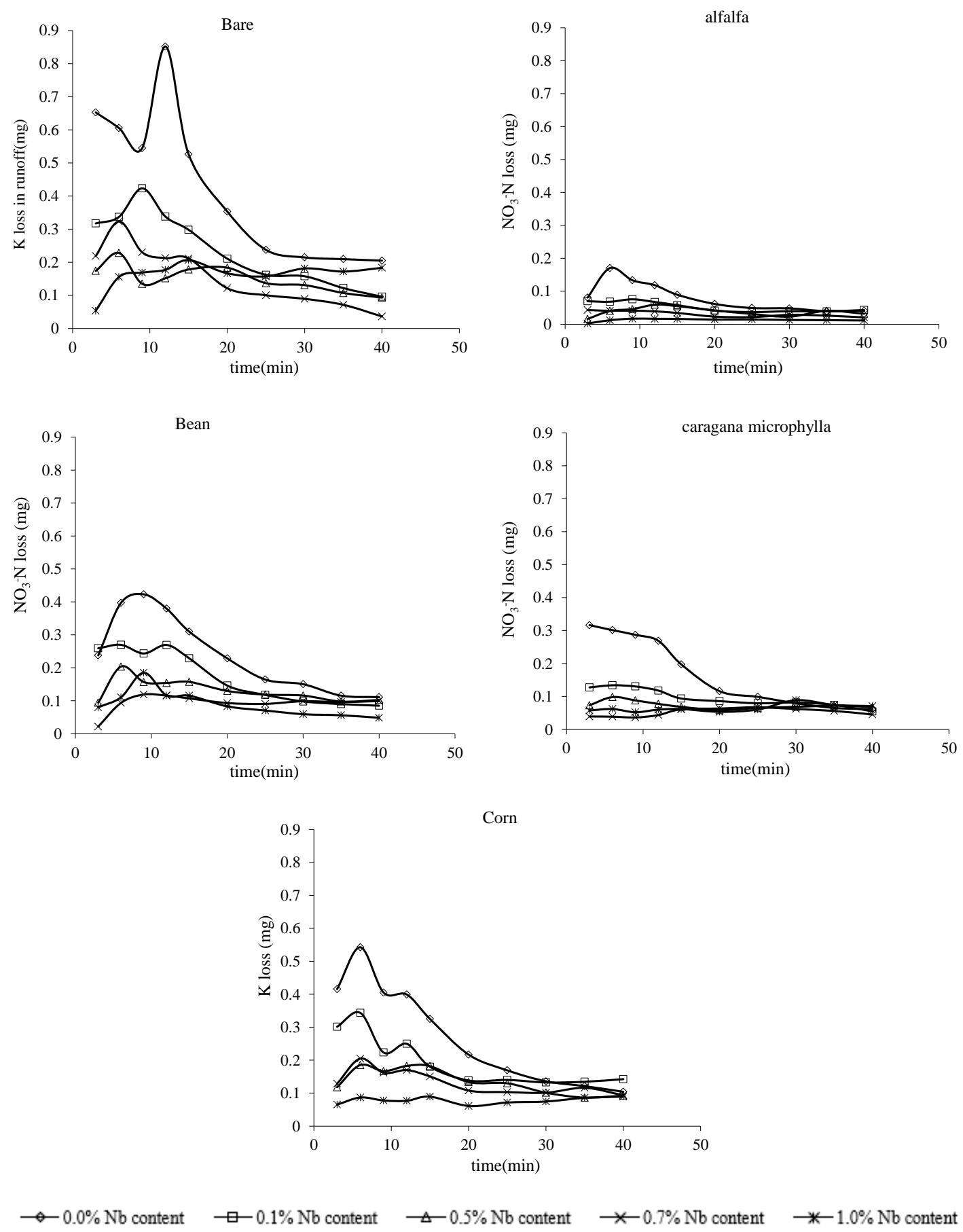

Figure 3. Effect of nano-biochar on nutrient losses in runoff, showing the averaged nitrogen $(N)$ mass loss as a function of time in two simulated rainfall events

\section{Effect of nano-biochar on nutrient loss in sediments}

Nutrient loss not only occurred in runoff but also in sediments. The amounts of nutrient loss and nutrient conservation values in sediments are shown in Tables 7 and 8. Similar to the nutrient loss in runoff, nutrient loss in sediments was the greatest in the bared plots. The nutrient loss in sediments was reduced effectively with the increase of 
nano-biochar contents. The lowest nutrient loss was found in plots with nano-biochar contents of $0.7 \%$ and $1.0 \%$. Nano-biochar delayed the initial runoff time and reduced the quantity of runoff hence soil loss by erosion. This resulted in less nutrient loss with sediment. Moreover, at the initial time, absorptive and dissolved nutrient was much higher, so nutrient loss in sediment was much higher. With further process of the simulated rainfall, more nutrient was washed away with soil particles. When the energy of soil adsorption and desorption was in a dynamic equilibrium, the nutrient contents in sediment tended to be stable. Besides, nutrient loss in sediments was less than that in runoff. The main reason was that nitrate nitrogen and potassium were hardly bound by soil particles and hence easily dissolved in the runoff. Moreover, phosphorus transport along slope was mainly controlled by water flow rather than by sediment movement (Osborne and Kovacic, 1993).

Table 8. Effect of nano-biochar on nutrient loss and conservation values $\left(C_{v}\right)$ in sediments

\begin{tabular}{|c|c|c|c|c|c|c|c|}
\hline $\begin{array}{c}\text { Vegetation } \\
\text { species }\end{array}$ & $\begin{array}{c}\text { Nano biochar } \\
\text { content }(\%)\end{array}$ & $\begin{array}{c}\mathrm{NO}_{3}-\mathrm{N} \text { loss } \\
(\mathrm{mg})\end{array}$ & $\begin{array}{c}C_{\mathrm{v}} \text { for } \\
\mathrm{NO}_{3}-\mathrm{N}(\%) \\
\end{array}$ & P los (mg) & $\begin{array}{c}C_{\mathrm{v}} \text { for } \mathrm{P} \\
(\%)\end{array}$ & $\begin{array}{c}\mathrm{K} \text { loss } \\
(\mathbf{m g})\end{array}$ & $\begin{array}{c}C_{\mathrm{v}} \text { for } \mathrm{K} \\
(\%)\end{array}$ \\
\hline \multirow{5}{*}{$\begin{array}{c}\text { Bare } \\
\text { (control) }\end{array}$} & 0 & 4.4 & 1 & 2.8 & 1 & 10.0 & I \\
\hline & 0.1 & 2.5 & 44.0 & 1.8 & 33.8 & 6.5 & 35.4 \\
\hline & 0.5 & 1.5 & 65.4 & 1.2 & 55.3 & 4.0 & 60.4 \\
\hline & 0.7 & 1.6 & 63.3 & 1.6 & 41.8 & 4.5 & 55.4 \\
\hline & 1 & 1.6 & 63.1 & 1.0 & 64.4 & 5.5 & 45.6 \\
\hline \multirow{5}{*}{$\begin{array}{c}\text { Caragana } \\
\text { microphylla }\end{array}$} & 0 & 2.5 & 42.6 & 1.5 & 46.9 & 5.7 & 43.3 \\
\hline & 0.1 & 1.8 & 58.8 & 1.1 & 60.0 & 4.5 & 55.0 \\
\hline & 0.5 & 1.3 & 69.7 & 0.9 & 67.6 & 3.7 & 62.7 \\
\hline & 0.7 & 0.9 & 78.6 & 0.6 & 78.9 & 2.7 & 73.4 \\
\hline & 1 & 0.9 & 79.0 & 0.7 & 74.2 & 2.4 & 76.3 \\
\hline \multirow{5}{*}{ Alfalfa } & 0 & 0.8 & 56.0 & 0.6 & 78.2 & 1.9 & 80.8 \\
\hline & 0.1 & 0.5 & 67.7 & 0.3 & 87.6 & 1.4 & 85.8 \\
\hline & 0.5 & 0.4 & 78.4 & 0.3 & 88.4 & 1.2 & 90.5 \\
\hline & 0.7 & 0.3 & 92.9 & 0.2 & 91.6 & 1.0 & 90.5 \\
\hline & 1 & 1 & 100.0 & 1 & 100.0 & 1 & 100.0 \\
\hline \multirow{5}{*}{ Bean } & 0 & 1.8 & 59.2 & 1.2 & 1.2 & 4.1 & 59.5 \\
\hline & 0.1 & 1.0 & 77.9 & 0.9 & 0.9 & 3.0 & 69.8 \\
\hline & 0.5 & 0.7 & 83.4 & 0.6 & 0.6 & 2.0 & 80.5 \\
\hline & 0.7 & 0.5 & 88.4 & 0.6 & 0.6 & 1.7 & 83.1 \\
\hline & 1 & 0.6 & 85.4 & 0.6 & 0.6 & 1.7 & 83.4 \\
\hline \multirow{5}{*}{ Corn } & 0 & 2.8 & 35.5 & 1.9 & 1.9 & 6.4 & 36.2 \\
\hline & 0.1 & 2.0 & 54.7 & 1.4 & 1.4 & 4.7 & 53.2 \\
\hline & 0.5 & 1.4 & 68.8 & 1.0 & 1.0 & 3.0 & 69.7 \\
\hline & 0.7 & 1.3 & 69.7 & 0.9 & 0.9 & 3.0 & 69.8 \\
\hline & 1 & 0.8 & 82.5 & 0.7 & 0.7 & 2.2 & 77.9 \\
\hline
\end{tabular}

Re: NB is short for nano-biochar 

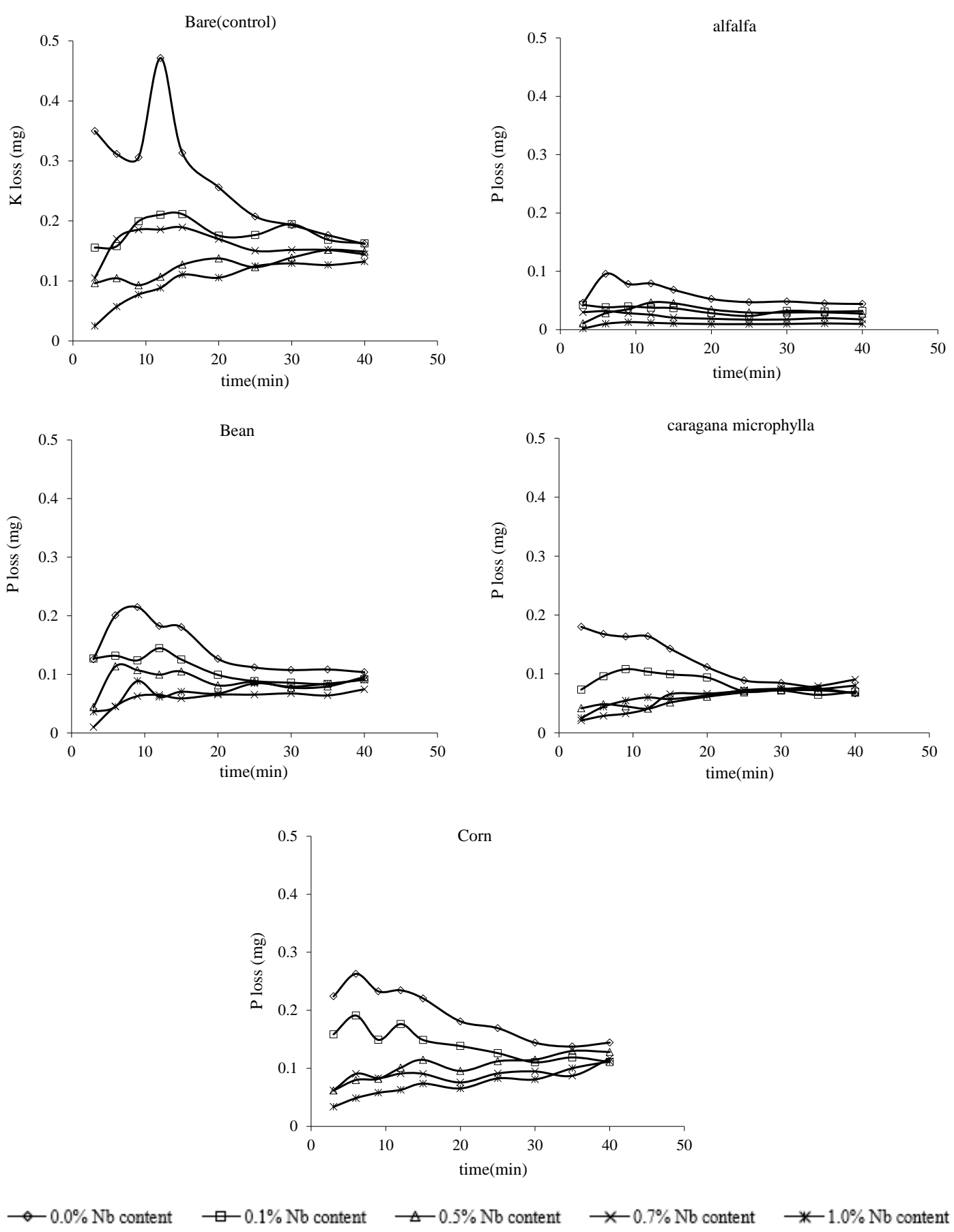

Figure 4. Effect of nano-biochar on nutrient losses in runoff, showing the averaged phosphorus $(P)$ mass loss as a function of time in two simulated rainfall events

The nutrient loss in plots with vegetation was much smaller comparing to that in bare. The main reason for that is vegetal cover could reduce the energy of rain drops falling on the soil surface. This in turn reduced the amount of eroded soils that move down the slope. Besides these, plots with vegetation would accumulate more decayed leaves. Due to decomposition of humus, mollusk will always exist (such as earthworms) (Lipiec et al., 2015) which could loosen the soil and make it for air and water to reach 
the roots of plants. As a result, loose soil and good structure improved soil infiltration rate. Meanwhile, for bare land, due to the impact and erosion of rain drops, the soil structure was damaged, resulting in the reduction or blockage of soil surface pores, which will lead to a significant decrease in soil infiltration rate. Thus, the nutrient will be easily lost. Among all the vegetation species considered in this study, alfalfa was the most efficient species to reduce the nutrient loss in sediments.
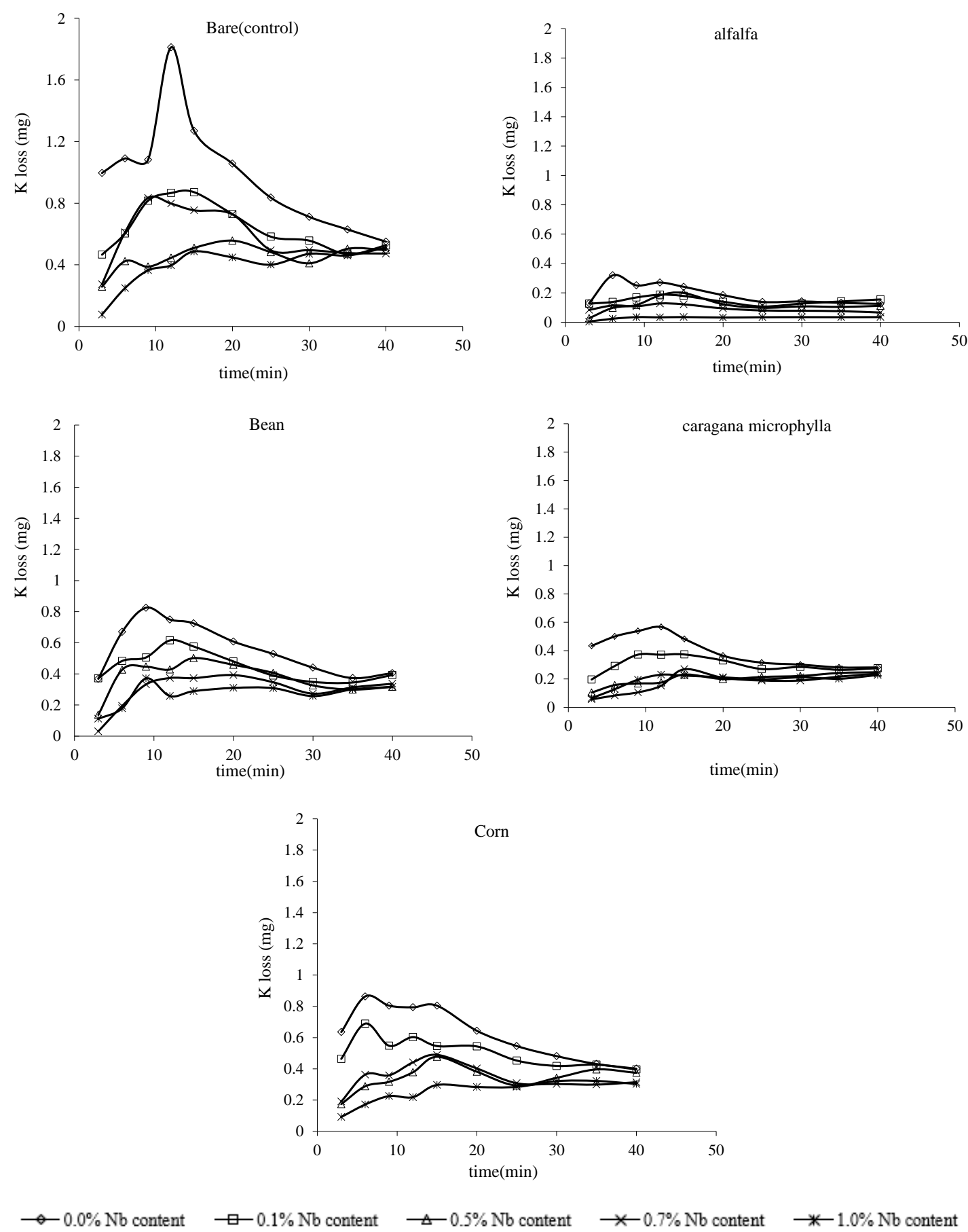

Figure 5. Effect of nano-biochar on nutrient losses in runoff, showing the averaged potassium $(K)$ mass lost as a function of time in two simulated rainfall events 
In general, the nano-biochar and even biochar is still at its initial research stage, most of the experiment related to soil and water conservation are conducted in pot experiment with short period. So long-term experiments are still needed to know the effects of nano-biochar application to control soil and water control better, as well as nutrient loss. Additionally, Sadeghi et al. (2016) and Li et al. (2107) also found biochar particles in the runoff, which indicated that biochar will be runoff easily with rainfall. So, in order to use biochar effectively, straw covering, manure or polyacrylamide, et al., could be used to help with coherence of biochar-soil particles and to avoid floating away by runoff. But in our study, no nano-biochar was found in runoff and soil sediment which showed a superior property to biochar. Moreover, high biochar rate such as 40 to 50 tons per hectare is always needed, together with its high mobility with storm runoff largely limits the its application. However, further comprehensive studies are still needed to examine the stability of nano-biochar in a long time before large-scale application of nano-biochar was used as a new soil amendment.

\section{Conclusion}

This study showed a positive effect of nano-biochar on the conservation of soil, water, and nutrients. We found that nano-biochar addition of more than $0.5 \%(0.131$ $\mathrm{t} / \mathrm{ha}$ on a mass basis) could delay the initial generation of runoff as well as reduce the amount of water runoff, soil erosion, and nutrient loss in a sandy soil of semi-arid loess region of China. Nutrient loss in runoff and sediment significantly decreased with the increase of nano-biochar content in all the treatments. Alfalfa was the most efficient species to conserve soil, water, and nutrient. The two-way ANOVA indicated that nanobiochar content and vegetation species had significant influences on soil water and nutrient conservation. Therefore, planting alfalfa with $0.131 \mathrm{t} / \mathrm{ha}$ nano-biochar in a sloping land have positive effects on soil and water conservation in the loess area. In the Loess Plateau of China, the wide application of vegetation cover has great influence on the treatment of soil erosion, and the combined application of nano-biochar will promote the effect of which more positive.

Acknowledgements. The research was fouded by the National Natural Science Foundation of China (Grant Nos. 41977007,4180713 and 41830754), the Science and Technology Program of Shaanxi Province (Grant No. 2018slkj-06) and Research project of State Key Laboratory of Eco-hydraulics in Northwest Arid Region of China (2019KJCXTD-4andQJNY-2019-01).

\section{REFERENCES}

[1] Bao, S. D. (2005): Soil Agricultural Chemistry Analysis. - China Agriculture Press, Beijing.

[2] Busscher, W. J., Novak, J. M., Ahmedna, M. (2011): Physical effects of organic matter amendment of a southeastern US coastal loamy sand. - Soil Science 176: 661-667.

[3] Chen, H. S., Shao, M. G., Li, Y. Y. (2008): Soil desiccation in the Loess Plateau of China. - Geoderma 143: 91-100.

[4] Cheng, C. H., Lehmann, J., Thies, J. E., Burton, S. D. (2015): Stability of black carbon in soils across a climatic gradient. - Journal of Geophysical Research Biogeosciences 113: $50-55$. 
[5] Deborah, A. B., Gwynn, R. J., Graig, A. S. (2011): Amending greenroof soil with biochar to affect runoff water quantity and quality. - Environmental Pollution 159: 2111-2118.

[6] Dutta, S., Mukhopadhyay, D. (2007): Dynamics of phosphorus sorption in some acid soils of West Bengal, India. - Asian Journal of Soil Science 2: 118-127.

[7] Guo, T. L., Wang, Q. J., Bai, W. J., Zhuang, J. (2013): Effect of land use on scouring flow hydraulics and transport of soil solute in erosion. - Journal of Hydrologic Engineering 18: 465-473.

[8] Herath, H. M. S. K., Camps-Arbestain, M., Hedley, M. (2013): Effect of biochar on soil physical properties in two contrasting soils, an Alfisol and an Andisol. - Geoderma 209210: $188-197$.

[9] Hillel, D. (1982): Introduction to Soil Physics. 5. Soil Water: Content and Potential. Elsevier, Amsterdam, pp. 57-89.

[10] Hina, K., Bishop, P., Arbestain, M. C., Calvelo-Pereira, R., and Macia-Agullo, J. A., Hindmarsh, J., Hanly, J. A., Macias, F., Hedley, M. J. (2010): Producing biochars with enhanced surface activity through alkaline pretreatment of feedstocks. - Australian Journal of Soil Research 48: 606-617.

[11] Huang, Y. M., Liu, D., An, S. S. (2015): Effects of slope aspect on soil nitrogen and microbial properties in the Chinese Loess region. - Catena 125: 135-145.

[12] Kumar, R., Srivastava, N. K. (1992): Conservation efficiency of five common riparian weeds in movement of soil, water and phosphorus. - Journal of Applied Ecology 29: 734 -744 .

[13] Laird, D., Fleming, P., Wang, B. Q., Horton, R., Karlen, D. (2010): Biochar impact on nutrient leaching from a Midwestern agricultural soil. - Geoderma 158: 436-442.

[14] Li, B., Bi, Z. C., Xiong, Z. Q. (2017b): Dynamic responses of nitrous oxide emission and nitrogen use efficiency to nitrogen and biochar amendment in an intensified vegetable field in southeastern China. - Global Change Biology Bioenergy 9: 1-14.

[15] Li, Y. P., Jia, Z. K., Han, Q. F., Wang, C. S., Xie, Y. Z., Wei, H. S. (2017a): Effects of mulching straw at different rates on water use pattern and soil properties of dry-land wheat. - Agricultural Research in the Arid Areas 35: 217-229 (in Chinese with English abstract).

[16] Li, Z. G., Gu, C. M., Zhang, R. H., Ibrahim, M., Zhang, G. S., Wang, L., Zhang, R. Q., Chen, F., Liu, Y. (2017c): The benefic effect induced by biochar on soil erosion and nutrient loss of slopping land under natural rainfall conditions in central China. Agricultural Water Management 185: 145-150.

[17] Lin, C. W., Tu, S. H., Huang, J. J., Chen, Y. B. (2009): The effect of plant hedgerows on the spatial distribution of soil erosion and soil fertility on sloping farmland in the purplesoil area of China. - Soil \& Tillage Research 105: 307-312.

[18] Lipiec, J., Turski, M., Hajnos, M., Swieboda, R. (2015): Pore structure, stability and water repellency of earthworm casts and natural aggregates in loess soil. - Geoderma 243: 124-129.

[19] Lu, S. J., Wang, Z. L. (2016): Research progress of soil conditioner polyacrylamide. Yellow River 38: 73-77 (in Chinese with English abstract).

[20] Lv, J. B., Zhou, B. B., Wang, Q. J. (2016): Influence of nano-biochar-soil layer applied subsurface on soil water movement. - Journal of Soil \& Water Conservation 12: 15-21. (in Chinese with English abstract).

[21] María, J. M., Bienes, Ramón, B., Luis, J., Raquel, P. R. (2007): Effect of vegetal cover on runoff and soil erosion under light intensity events. Rainfall simulation over USLE plots. - Science of the Total Environment 378: 161-165.

[22] Mukherjee, A., Zimmerman, A. R. (2013): Organic carbon and nutrient release from a range of laboratory-produced; biochars and biochar-soil mixtures. - Geoderma 193: 122130 . 
[23] Nguyen, B. T., Lehmann, J., Hockaday, W. C., Joseph, S., Masiello, C. A. (2010): Temperature sensitivity of black carbon decomposition and oxidation. - Environmental Science \& Technology 44: 3324-3331.

[24] Osborne, L. L., Kovacic, D. A. (1993): Riparian vegetated buffer strips in water-quality restoration and stream management. - Freshwater Biology 29: 243-258.

[25] Peng, X., Zhu, Q. H., Xie, Z. B., Darboux, F., Holden, N. M. (2016): The impact of manure, straw and biochar amendments on aggregation and erosion in a hillslope Ultisol. - Catena 138: 30-37.

[26] Poss, R., Fardeau, J. C., Saragonit, H., Quantin, P. (2010): Potassium release and fixation in Ferralsols (Oxisols) from Southern Togo. - European Journal of Soil Science 42: 649660.

[27] Rahma, A. E., Wang, W., Tang, Z., Lei, T. W., Warrington, D. N., Zhao, J. (2017): Straw mulch can induce greater soil losses from loess slopes than no mulch under extreme rainfall conditions. - Agricultural \& Forest Meteorology 232: 141-151.

[28] Sadeghi, S. H., Hazbavi, Z., Harchegani, M. K. (2016): Controllability of runoff and soil loss from small plots treated by vinasse-produced biochar. - Science of the Total Environment 541: 483-490.

[29] Shi, H., Shao, M. A. (2000): Soil and water loss from the Loess Plateau in China. Journal of Arid Environments 45: 9-20.

[30] Smetanová, A., Dotterweich, M., Diehl, D. (2013): Influence of biochar and terra preta substrates on wettability and erodibility of soils. - Zeitschrift für Geomorphologie 57: 111-134.

[31] Srivastava, P., Singh, S. (2012): Conservation of soil, water and nutrients in surface runoff using riparian plant species. - Journal of Environmental Biology 33: 43-49.

[32] Sun, H., Tang, Y., Wang, C., He, Y. H. (2001): Contour hedgerow intercropping for exploitation and conservation of slope cropland in mountain areas. - Journal of Mountain Research 29: 125-129 (in Chinese with English abstract).

[33] Tomer, M. D., Moorman, T. B., Kovar, J. L., James, D. E., Burkart, M. R. (2007): Spatial patterns of sediment and phosphorus in a riparian buffer in western Iowa. - Journal of Soil \& Water Conservation 62: 329-338.

[34] Vadas, P. A., Busch, D. L., Powell, J. M., Brink, G. E. (2015): Monitoring runoff from cattle-grazed pastures for a phosphorus loss quantification tool. - Agriculture Ecosystems \& Environment 199: 124-131.

[35] Wang, C., Walter, M. T., Parlange, J. Y. (2013): Modeling simple experiments of biochar erosion from soil. - Journal of Hydrology 499: 140-145.

[36] Wang, L. H., Dalabay, N., Lu, P., Wu, F. Q. (2017): Effects of tillage practices and slope on runoff and erosion of soil from the Loess Plateau, China, subjected to simulated rainfall. - Soil \& Tillage Research 166: 147-156.

[37] Wozniak, A., Kwiatkowski, C. (2013): Effect of long-term reduced tillage on yield and weeds of spring barley. - Journal of Agricultural Science \& Technology 15: 1335-1342.

[38] Wu, S. F., Wu, P. T., Feng, H., Merkley, G. P. (2011): Effects of alfalfa coverage on runoff, erosion and hydraulic characteristics of overland flow on loess slope plots. Frontiers of Environmental Science \& Engineering in China 5: 76-83.

[39] Yan, W. J., Zhang, S. (1999): Loss and prediction of bio available phosphorus in surface runoff under simulated rainfall condition. - Environmental Chemistry 18: 497-506 (in Chinese with English abstract).

[40] Zhou, B. B., Hu, Z. C., Wang, Q. J. (2015): Pinhole type artificial field simulated rainfall device with anti-clogging. - China ZL2015100694924. 